\title{
COPD and the risk of mild cognitive impairment and dementia: a cohort study based on the Chinese Longitudinal Health Longevity Survey
}

This article was published in the following Dove Medical Press journal: International Journal of COPD

Fei Xie

Lixin Xie

Department of Pulmonary and Critical Care Medicine, Chinese PLA General Hospital, Beijing 100853, China
Correspondence: Lixin Xie Department of Pulmonary and Critical Care Medicine, Chinese PLA General Hospital, 28 Fuxing Road, Beijing 100853, China

Tel +86 I06687 64I5

Email xielixin30Ihuxi@I63.com
Background: COPD may lead to cognitive impairment or even dementia. However, the current conclusions are inconsistent with little evidence from prospective, large-sample studies. This study was designed to explore the association of COPD with mild cognitive impairment (MCI) and dementia risk based on a cohort study.

Patients and methods: All participants were from the Chinese Longitudinal Health Longevity Survey (CLHLS) 2011/2012 waves. The follow-up survey was conducted in 2014 and the incidence of MCI and dementia were recorded.

Results: During the 3-year follow-up period, 712 new cases of MCI and 83 new cases of dementia were diagnosed. The incidence of MCI and dementia were higher in those with COPD than those without COPD at baseline. Cox analysis showed that the HRs of COPD for MCI and dementia incidence were 1.486 (95\% CI: 1.207-1.855) and 1.896 (95\% CI: 1.079-3.330), respectively after adjusting for related covariates. For different baseline smoking status, those who were current smokers had the highest HRs of COPD for MCI and dementia.

Conclusion: Baseline COPD was independently associated with increased risk of MCI and dementia incidence among Chinese elderly, and the association was more pronounced among those who were current smokers.

Keywords: chronic obstructive pulmonary disease, dementia, cohort

\section{Background}

COPD has become an important public health problem all over the world. ${ }^{1,2}$ In China, COPD has also become the third leading cause of death and the second leading cause of quality of life, along with increased smoking rate, air pollution, and coal burning issues. ${ }^{3}$ Additionally, unlike the Western developed countries, there are some serious issues related to the low level of diagnosis and treatment of COPD in China. Data showed that only $35.0 \%$ of the patients were aware of their COPD condition or diagnosed by doctors, and more than half of the patients with definite diagnosis discontinued medication voluntarily. ${ }^{4}$ This low awareness rate and inadequate treatment have resulted in severe complications and severe impact on quality of life..$^{5,6}$

As we know, COPD is associated with a series of comorbidities, including ischemic heart disease, hypertension, diabetes, lung cancer, and so on. ${ }^{7}$ In addition, recent studies have shown that COPD was associated with neurological impairment, cognitive decline, and even dementia. ${ }^{8,9}$ However, there have been no conclusive evidences yet, and most of the related studies were cross-sectional or case-control design, based on inpatients with small samples size. ${ }^{10-12}$ There has been little evidence based on prospective, large-sample studies. ${ }^{13}$ Hence, we used the data from a representative 
large-sample cohort of Chinese elderly from the community to investigate the relationship between baseline COPD status and cognitive decline, and also to explore the impact of smoking on this association.

\section{Patients and methods}

\section{Study population}

The data used in this study are from the Chinese Longitudinal Health Longevity Survey (CLHLS) 2011/2012 wave. Details of the design and investigation plan for the study can be found in previously published literature. ${ }^{14}$ All the related information including demographics, disease history, and cognitive function (mini-mental state examination, [MMSE]) was collected by trained staff. The follow-up survey was conducted in 2014, and the cognitive function and dementia incidence were calculated as the outcome variables.

The flow chart of research participants included was shown in Figure 1. In 2011/2012 survey wave, there were a total of 9,765 Chinese elderly from the community included. After excluding those who lacked follow-up information, were missing important variable data, or had been diagnosed with mild cognitive impairment (MCI) or dementia at baseline, finally, there remained 4,735 elderly who fully qualified for the data analysis.

\section{Definitions}

MCI was defined as positive if the MMSE score was below 17 for illiterate participants, below 20 for those with 1-6 years of education, or below 24 for those who had over 6 years

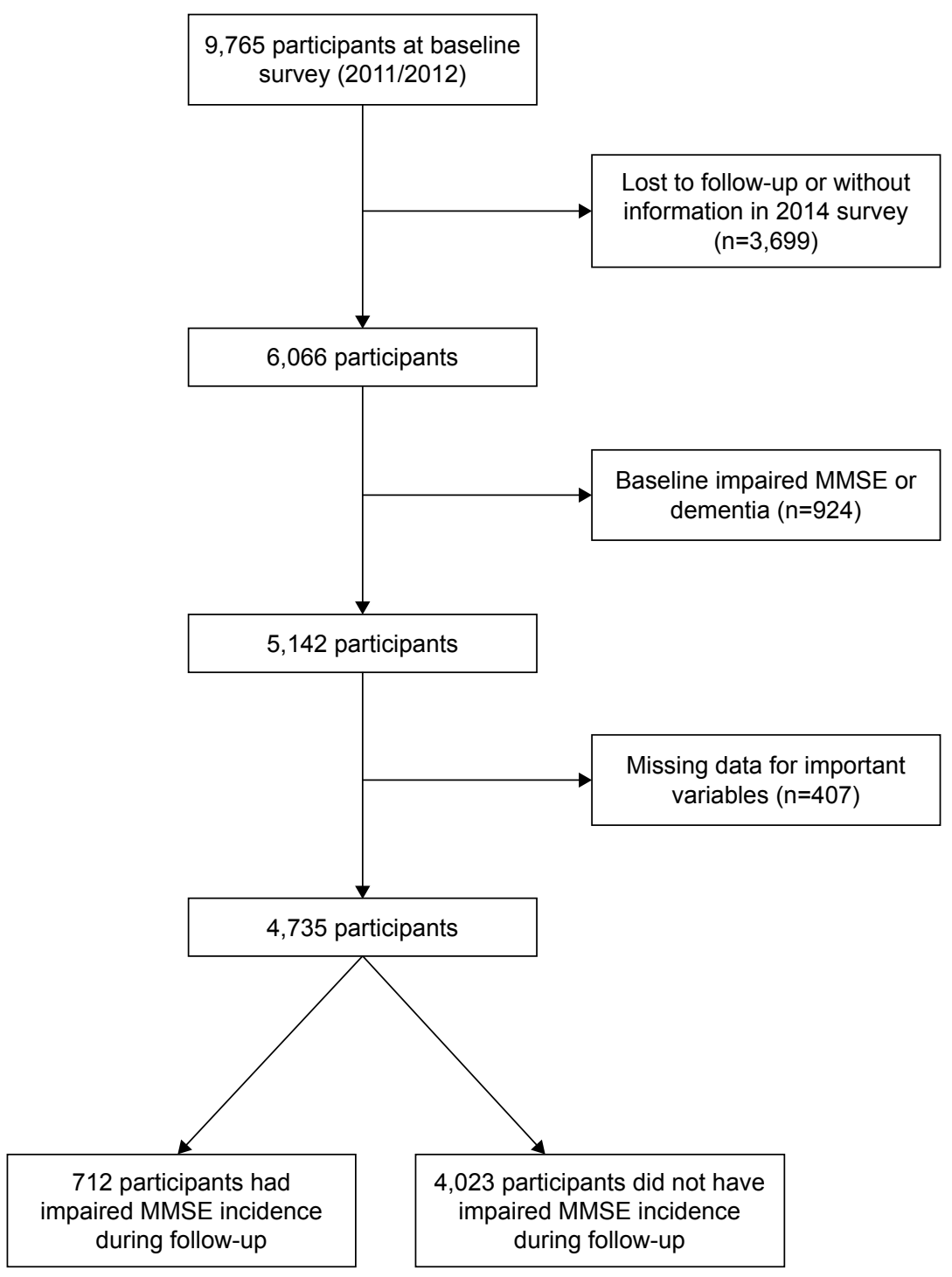

Figure I Flowchart of inclusion of participants.

Abbreviation: MMSE, mini-mental state examination. 
of education among Chinese people. COPD diagnosis was recorded based on the self-report.

Smoking and alcohol drinking status were recorded and divided into three categories (current, ever, never) according to the questionnaire.

\section{Statistical analyses}

The continuous variable was expressed as mean $\pm \mathrm{SD}$, and the categorical variable was expressed as n (\%). Student's $t$-test/variance analysis and chi-squared test were used for comparison between groups. Cox proportional hazards model was used to calculate HRs and 95\% CI. We calculated the HRs of COPD for both MCI and dementia incidence, and adjusted related variables. $P<0.05$ was considered as statistically significant, and all analyses were conducted using SPSS software (version 22.0, IBM Corporation, Armonk, NY, USA).

\section{Ethics approval and consent to participate}

The study was approved by the Biomedical Ethics Committee of Peking University and each respondent signed a written informed consent.

\section{Results}

Baseline characteristics of 4,735 elderly were listed in Table 1 . The average age was $82.91 \pm 9.74$ years, $42.5 \%$ of the elderly were illiterate, $52.8 \%$ were divorced/widowed, and only approximately $20.0 \%$ were currently smoking and drinking alcohol. Regarding gender, female elderly had older age, higher body mass index (BMI) and blood pressure levels, lower education level, and lower smoking and alcohol drinking rates $(P<0.05)$. The prevalence of hypertension, diabetes, and stroke did not show a gender difference $(P>0.05)$. A total of $515(10.9 \%)$ people had baseline COPD and the baseline MMSE score was $22.87+3.52$.

\section{Incidence of $\mathrm{MCl}$ and dementia according to baseline COPD status}

During the 13,496 person-years of follow-up, there were a total of 712 newly diagnosed MCI cases. The incidence in 3 years was $15.0 \%$ (95\% CI: $14.0 \%-16.1 \%)$, and the incidence density was 5.3 (95\% CI: 4.9-5.7) per 100 personyears. A sum of 83 cases of new onset dementia was diagnosed. The incidence rate was 1.8\% (95\% CI: $1.4 \%-2.1 \%)$ in 3 years, and the incidence density was $0.6(0.5-0.8)$ per 100 person-years. The incidence of both MCI and dementia was higher in those with COPD than in those without COPD at baseline $(P<0.05)$ (Table 2$)$.

\section{$\mathrm{HRs}$ and $95 \% \mathrm{Cl}$ of $\mathrm{MCl}$ and dementia incidence according to baseline COPD and smoking status}

Table 3 showed the HRs of baseline COPD for MCI and dementia incidence during follow-up according to baseline smoking status. Cox analysis showed that the HRs of MCI and dementia incidence caused by COPD were 1.691 (95\% CI: 1.442-1.999) and 1.996 (95\% CI: 1.226-3.341), respectively. After adjusting for age, gender, marital status, education level, alcohol drinking, current exercise, baseline BMI, baseline prevalence of hypertension, diabetes, and stroke, the adjusted HRs were 1.486 (95\% CI: 1.207-1.855) and 1.896 (95\% CI: 1.079-3.330), respectively. For different baseline smoking status, the adjusted HRs of COPD for MCI and dementia incidence were higher in those who were currently smoking at baseline, the HRs and 95\% CI were 2.281 (95\% CI: 1.443-3.608) and 3.378 (95\% CI: 1.088-10.490) respectively, compared with the general population.

\section{Discussion}

This large-sample, community-based cohort study revealed that baseline COPD status was independently associated with both MCI and dementia incidence, and this association was affected by smoking status.

COPD is a common chronic disease which is associated with abnormal lung inflammation caused by harmful gases or particles, characterized by persistent airflow restriction, and often further leads to pulmonary heart disease and/ or respiratory failure. Some studies have focused on its relationship with neurologic function, but with inconsistent conclusions. ${ }^{12}$ Data based on the Atherosclerosis Risk in Communities (ARIC) study showed that reduced lung function was associated with poor cognitive performance and higher risk of dementia hospitalization. ${ }^{15}$ Data based on Taiwanese National Health Insurance Research Database showed that COPD patients exhibited a 1.27-fold higher risk of developing dementia. ${ }^{13}$ The results of the cohort study presented in this study were in agreement with most of the previous results. Baseline COPD status was independently associated with MCI and dementia incidence, providing prospective evidence for the association.

Smoking status affected the association between COPD and cognitive function, including both MCI and dementia. Results showed that this association was predominant among those who were current smokers. There are limited studies on this topic. Evidence has shown that smoking produces harmful gases and particles, the culprit of abnormal inflammation, and consequently results in airflow restriction and 
Table I Baseline characteristics of participants

\begin{tabular}{|c|c|c|c|c|}
\hline \multirow[t]{2}{*}{ Characteristics } & \multirow[t]{2}{*}{ Total $(n=4,735)$} & \multicolumn{2}{|l|}{ Gender } & \multirow[t]{2}{*}{$P$-value } \\
\hline & & Male $(n=2,173)$ & Female $(n=2,562)$ & \\
\hline \multicolumn{5}{|l|}{ Mean \pm SD } \\
\hline Age (years) & $82.91 \pm 9.74$ & $82.21 \pm 9.33$ & $83.74 \pm 10.13$ & $<0.00 \mathrm{I}$ \\
\hline BMI $\left(\mathrm{kg} / \mathrm{m}^{2}\right)$ & $21.98 \pm 4.01$ & $21.86 \pm 3.59$ & $22.12 \pm 4.46$ & 0.032 \\
\hline $\mathrm{SBP}(\mathrm{mmHg})$ & $137.18 \pm 20.47$ & $136.09 \pm 19.95$ & $138.46 \pm 20.99$ & $<0.00 \mathrm{I}$ \\
\hline $\mathrm{DBP}(\mathrm{mmHg})$ & $80.88 \pm I I .88$ & $80.96 \pm I I .54$ & $80.77 \pm 12.24$ & 0.578 \\
\hline MMSE score & $22.87 \pm 3.52$ & $23.02 \pm 3.05$ & $22.70 \pm 3.87$ & 0.081 \\
\hline \multicolumn{5}{|l|}{$\mathbf{N}(\%)$} \\
\hline Education (years) & & & & $<0.00 \mathrm{I}$ \\
\hline 0 years & $2,012(42.5)$ & $493(33.1)$ & I,519 (59.2) & \\
\hline $1-6$ years & I,969 (4I.6) & $\mathrm{I}, 226(45 . \mathrm{I})$ & $743(29.0)$ & \\
\hline$\geq 7$ years & $754(15.9)$ & $454(21.8)$ & $300(11.7)$ & \\
\hline Marital status & & & & $<0.00 \mathrm{I}$ \\
\hline Married & $2,234(47.2)$ & $892(4 I .0)$ & I,342 (52.4) & \\
\hline Widowed/divorced/other & $2,50 \mathrm{I}(52.8)$ & $\mathrm{I}, 28 \mathrm{I}(59.0)$ & I,220 (47.6) & \\
\hline Smoking & & & & $<0.001$ \\
\hline Current & I,092 (23.1) & $808(37.2)$ & $284(11.1)$ & \\
\hline Ever & $802(16.9)$ & $575(26.5)$ & $227(8.9)$ & \\
\hline Never & $2,84 I(60.0)$ & $790(36.3)$ & $2,05 I(80.0)$ & \\
\hline Alcohol drinking & & & & $<0.001$ \\
\hline Current & $\mathrm{I}, 004(2 \mathrm{I} .2)$ & $702(32.3)$ & $302(11.8)$ & \\
\hline Ever & $699(14.8)$ & $480(22.1)$ & $219(8.5)$ & \\
\hline Never & $3,032(64.0)$ & $991(45.6)$ & $2,04 I(79.7)$ & \\
\hline Current exercise & & & & 0.007 \\
\hline Yes & I,950 (4I.2) & $849(39.1)$ & $\mathrm{I}, 10 \mathrm{I}(43.0)$ & \\
\hline No & 2,785 (58.8) & I,324 (60.9) & $\mathrm{I}, 46 \mathrm{I}(57.0)$ & \\
\hline Hypertension & & & & 0.102 \\
\hline Yes & $\mathrm{I}, 433(30.3)$ & $664(30.6)$ & $769(30.0)$ & \\
\hline No & $3,302(69.7)$ & I,509 (69.4) & I,793 (70.0) & \\
\hline Diabetes & & & & 0.489 \\
\hline Yes & $782(16.5)$ & $361(16.6)$ & $421(16.4)$ & \\
\hline No & 3,953 (83.5) & $\mathrm{I}, 812(82.4)$ & $2,141(83.6)$ & \\
\hline Stroke & & & & 0.531 \\
\hline Yes & $350(7.4)$ & I55 (7.I) & $195(7.6)$ & \\
\hline No & 4,385 (92.6) & $2,018(92.9)$ & $2,367(92.4)$ & \\
\hline COPD & & & & $<0.001$ \\
\hline Yes & $515(10.9)$ & $194(8.9)$ & $321(12.5)$ & \\
\hline No & $4,220(89.1)$ & I,979 (9I.I) & $2,24 I(87.5)$ & \\
\hline
\end{tabular}

Note: Data are mean \pm SD for continuous values or \% for category values.

Abbreviations: BMI, body mass index; MMSE, mini-mental state examination.

finally hypoxia, ${ }^{16,17}$ which was the main cause of cognitive impairment induced by COPD. ${ }^{18,19}$ This suggests that smoking cessation cannot only improve lung function and slow down COPD progression, but also improve neuronal function decline caused by COPD.
This study has several advantages. CLHLS is a welldesigned, long-term follow-up, reliable, large-sample, representative cohort study of the elderly in China. In addition, unlike previous retrospective studies or small-sample studies, this study provided prospective evidence about the impact 
Table 2 Incidence of mild cognitive impairment $(\mathrm{MCl})$ and dementia according to baseline COPD status

\begin{tabular}{|c|c|c|c|}
\hline \multirow[t]{2}{*}{ Variables } & \multicolumn{2}{|c|}{ Baseline COPD status } & \multirow[t]{2}{*}{ Total $(n=4,735)$} \\
\hline & Yes $(n=5 \mid 5)$ & No $(n=4,220)$ & \\
\hline \multicolumn{4}{|l|}{ Total } \\
\hline \multicolumn{4}{|l|}{$\mathrm{MCl}$} \\
\hline Number of incident cases & 97 & 615 & 712 \\
\hline Incidence (\%) & $18.8(15.5-22.2)$ & $14.6(13.5-15.6)$ & $15.0(14.0-16.1)$ \\
\hline Total person-years & 1,469 & 12,027 & 13,496 \\
\hline Incidence rate (per I00 person-years) & $6.6(5.3-7.9)$ & $5.1(4.7-5.5)$ & $5.3(4.9-5.7)$ \\
\hline \multicolumn{4}{|l|}{ Dementia } \\
\hline Number of incident cases & 15 & 68 & 83 \\
\hline Incidence (\%) & $2.9(1.5-4.4)$ & $1.6(1.2-2.0)$ & $1.8(1.4-2.1)$ \\
\hline Total person-years & I,456 & 11,948 & 13,404 \\
\hline Incidence rate (per I00 person-years) & $1.0(0.5-1.5)$ & $0.6(0.4-0.7)$ & $0.6(0.5-0.8)$ \\
\hline
\end{tabular}

of COPD on cognitive function based on a large sample of elderly population in a 3-year cohort study.

On the other hand, there were still some deficiencies in this study. Firstly, all the disease information came from the subjects' self-report, and there were certainly some cases of under-reporting, which reduced the effect. Secondly, the

Table 3 HRs and $95 \% \mathrm{Cl}$ of baseline COPD status for mild cognitive impairment $(\mathrm{MCl})$ and dementia incidence according to gender and smoking status

\begin{tabular}{|c|c|c|c|}
\hline Variables & Models & HR (95\% Cl) & $P$-value \\
\hline \multicolumn{4}{|l|}{ Total } \\
\hline \multirow[t]{4}{*}{$\mathrm{MCl}$} & Crude model & 1.691 (1.442-1.999) & $<0.00 \mathrm{I}$ \\
\hline & Model I & $1.518(1.225-1.882)$ & $<0.00 \mathrm{I}$ \\
\hline & Model 2 & $1.497(1.208-1.856)$ & $<0.001$ \\
\hline & Model 3 & 1.486 (1.207-1.855) & $<0.00 \mathrm{I}$ \\
\hline \multirow[t]{4}{*}{ Dementia } & Crude model & $1.996(1.226-3.34 I)$ & 0.040 \\
\hline & Model I & $1.917(1.092-3.365)$ & 0.023 \\
\hline & Model 2 & $1.899(1.078-3.346)$ & 0.026 \\
\hline & Model 3 & $1.896(1.079-3.330)$ & 0.026 \\
\hline \multicolumn{4}{|c|}{ Currently smoking } \\
\hline \multirow[t]{4}{*}{$\mathrm{MCl}$} & Crude model & $2.34 \mid(1.516-3.616)$ & $<0.001$ \\
\hline & Model I & $2.262(1.455-3.518)$ & $<0.00 \mathrm{I}$ \\
\hline & Model 2 & $2.244(1.426-3.530)$ & $<0.00 \mathrm{I}$ \\
\hline & Model 3 & $2.281(1.443-3.608)$ & $<0.001$ \\
\hline \multirow[t]{4}{*}{ Dementia } & Crude model & $3.482(1.165-10.402)$ & 0.025 \\
\hline & Model I & 3.261 (1.082-9.827) & 0.036 \\
\hline & Model 2 & $3.425(1.117-10.502)$ & 0.031 \\
\hline & Model 3 & $3.378(1.088-10.490)$ & 0.035 \\
\hline
\end{tabular}

Notes: Model I: adjusted for age, gender, marital status, education level. Model 2: adjusted for alcohol drinking, current exercise, baseline body mass index, plus those adjusted in model I (smoking status was included in the model with total population). Model 3: adjusted for baseline prevalence of hypertension, diabetes, stroke, plus those adjusted in model 2. study removed those who had MCI at baseline, retaining only those with normal cognitive function, so the incidence of dementia was lower. Thirdly, we lacked information about COPD treatment and control status. Therefore, it is impossible to compare the risk of cognitive impairment between patients who received treatment and those who did not. Fourth, we did not have information on specific types of dementia, such as Alzheimer's or vascular dementia or other types, so it is impossible to distinguish the different effects of COPD on specific types of dementia.

\section{Conclusion}

In summary, the results of this study showed that COPD was an important and independent risk factor for cognitive function and dementia in the elderly, and the association was more pronounced among those who were current smokers. This suggested that clinicians should not only pay attention to the effect of COPD on cardiopulmonary function, but also on cognitive function, to avoid more serious cognitive impairment and reduce disease burden, especially among smokers.

\section{Data sharing statement}

All data used in this study were stored at Peking University (http://opendata.pku.edu.cn/) and are available upon request.

\section{Acknowledgments}

We thank the CLSHL research team and the National Development Research Institute of Peking University. This study was supported by research grants from the Clinical Support Project of Chinese PLA General Hospital (2018FCWJFWZX-2-04) and Translational Medicine of Chinese PLA General Hospital (2018TM-03). The views and opinions 
expressed in this paper are those of the authors and do not necessarily reflect the official position of the study sponsors.

\section{Author contributions}

All authors contributed toward data analysis, drafting and revising the paper, gave final approval of the version to be published and agree to be accountable for all aspects of the work.

\section{Disclosure}

The authors report no conflicts of interest in this work.

\section{References}

1. Chayut P, Kanitta B, Kenji S. Diseases burden of chronic obstructive pulmonary disease (COPD) attributable to ground-level ozone in Thailand: estimates based on surface monitoring measurements data. Glob J Health Sci. 2016;8(1):1-13.

2. Pauwels RA, Rabe KF. Burden and clinical features of chronic obstructive pulmonary disease (COPD). Lancet. 2004;364(9434):613-620.

3. Chan KY, Li X, Chen W, et al. Prevalence of chronic obstructive pulmonary disease (COPD) in China in 1990 and 2010. J Glob Health. 2017;7(2):020704.

4. Zhong N, Wang C, Yao W, et al. Prevalence of chronic obstructive pulmonary disease in China: a large, population-based survey. Am J Respir Crit Care Med. 2007;176(8):753.

5. de Miguel Díez J, Jiménez García R, Hernández Barrera V, et al. Trends in self-rated health status and health services use in COPD patients (2006-2012). A Spanish population-based survey. Lung. 2015;193(1): $53-62$.

6. Wacker ME, Jörres RA, Karch A, et al. Assessing health-related quality of life in COPD: comparing generic and disease-specific instruments with focus on comorbidities. BMC Pulm Med. 2016;16(1):70.

7. Carlin BW. COPD and associated comorbidities: a review of current diagnosis and treatment. Postgrad Med. 2012;124(4):225-240.
8. Kakkera K, Padala KP, Kodali M, Padala PR. Association of chronic obstructive pulmonary disease with mild cognitive impairment and dementia. Curr Opin Pulm Med. 2017;24(2):1.

9. Thakur N, Blanc PD, Julian LJ. COPD and cognitive impairment: the role of hypoxemia and oxygen therapy. Int J Chron Obstruct Pulmon Dis. 2010;2010:263-269.

10. Hung WW, Wisnivesky JP, Siu AL, Ross JS. Cognitive decline among patients with chronic obstructive pulmonary disease. Am J Respir Crit Care Med. 2009;180(2):134-137.

11. Antonelli Incalzi R, Marra C, Giordano A, et al. Cognitive impairment in chronic obstructive pulmonary disease. Journal of Neurology. 2003;250(3):325-332.

12. Schou L, Østergaard B, Rasmussen LS, Rydahl-Hansen S, Phanareth K. Cognitive dysfunction in patients with chronic obstructive pulmonary disease - a systematic review. Respir Med. 2012;106(8):1071-1081.

13. Liao WC, Lin CL, Chang SN, Tu CY, Kao CH. The association between chronic obstructive pulmonary disease and dementia: a populationbased retrospective cohort study. Eur J Neurol. 2015;22(2):334-340.

14. Zeng Y. Chinese longitudinal healthy longevity survey and some research findings. Geriatr Gerontol Int. 2004;4(s1):S49-S52.

15. Pathan SS, Gottesman RF, Mosley TH, Knopman DS, Sharrett AR, Alonso A. Association of lung function with cognitive decline and dementia: the Atherosclerosis Risk in Communities (ARIC) study. Eur J Neurol. 2011;18(6):888-898.

16. Osaka D, Shibata Y, Abe S, et al. Relationship between habit of cigarette smoking and airflow limitation in healthy Japanese individuals: the Takahata study. Intern Med. 2010;49(15):1489-1499.

17. Yoshimoto D, Nakano Y, Onishi K, Hagan G, Jones P. The relationship between the COPD assessment test score and airflow limitation in Japan in patients aged over 40 years with a smoking history. Int $J$ Chron Obstruct Pulmon Dis. 2014;9:1357-1363.

18. Zheng GQ, Wang Y, Wang XT. Chronic hypoxia-hypercapnia influences cognitive function: a possible new model of cognitive dysfunction in chronic obstructive pulmonary disease. Med Hypotheses. 2008;71(1):111-113.

19. Torres-Sánchez I, Rodríguez-Alzueta E, Cabrera-Martos I, LópezTorres I, Moreno-Ramírez MP, Valenza MC. Cognitive impairment in COPD: a systematic review. J Bras Pneumol. 2015;41(2):182-190.
International Journal of COPD

\section{Publish your work in this journal}

The International Journal of COPD is an international, peer-reviewed journal of therapeutics and pharmacology focusing on concise rapid reporting of clinical studies and reviews in COPD. Special focus is given to the pathophysiological processes underlying the disease, intervention programs, patient focused education, and self management protocols.

\section{Dovepress}

This journal is indexed on PubMed Central, MedLine and CAS. The manuscript management system is completely online and includes a very quick and fair peer-review system, which is all easy to use. Visit http://www.dovepress.com/testimonials.php to read real quotes from published authors. 